\title{
Salmonella enterica Serovar Typhi: Molecular Analysis of Strains with Decreased Susceptibility and Resistant to Ciprofloxacin in India from 2001-2003
}

\author{
Malini R. Capoor ${ }^{1}$, Deepthi Nair ${ }^{1}$, Pushpa Aggarwal' ${ }^{1}$, Vanessa Mathys ${ }^{2}$, Marie Dehem ${ }^{3}$ and Pablo Juan Bifani ${ }^{2}$ \\ ${ }^{1}$ Department of Microbiology, Vardhman Mahaveer Medical College and Safdarjung Hospital; New Delhi, India; ${ }^{2}$ Department of Molecular \\ Biology, Pasteur Institute; Brussels, Belgium; ${ }^{3}$ Genoscreen, Campus Pasteur-Lille; France
}

\begin{abstract}
Chromosomally-mediated reduced susceptibility to ciprofloxacin narrows the therapeutic options in enteric fever. We made a molecular comparison of clinical isolates of fluoroquinolone-resistant strains of Salmonella enterica serotype Typhi from January 2001 to May 2003; 178 isolates were subjected to antimicrobial susceptibility testing by the Kirby-Bauer method of disk diffusion, and agar dilution was used to determine the minimum inhibitory concentration (MIC) to ciprofloxacin. Nalidixic-acid resistant strains (NARST) were observed in $51 \%$ of the isolates, of which $98.9 \%$ had decreased susceptibility $(\mathrm{MIC} \geq 0.125-1 \mu \mathrm{g} / \mathrm{mL})$ to ciprofloxacin. A single strain $(4 \mu \mathrm{g} / \mathrm{mL}) \mathrm{was}$ resistant to ciprofloxacin and double mutations were found in the gyrA gene (76 Asp $\rightarrow$ Asn, 44 leu $\rightarrow$ Ileu). Among seven NARST strains with reduced susceptibility, a single mutation was found in five strains, one of which had 76 Asp $\rightarrow$ Asn and two each had mutations at $87 \mathrm{Asp} \rightarrow$ Asn and 72 Phe $\rightarrow$ Tyr, respectively); no mutations could be detected in two isolates. Routine antimicrobial surveillance, coupled with molecular analysis of fluoroquinolone resistance, is crucial for revision of enteric fever therapeutics.
\end{abstract}

Key-Words: Salmonella enterica, S.Typhi, ciprofloxacin, resistance.

The antibiotics that have been traditionally incorporated into the therapy of enteric fever have been ampicillin, chloramphenicol, sulfamethoxazole-trimethoprim and tetracycline. However, with the evolution of plasmidencoded multi-drug resistance (MDR) to these drugs in the 1970s and 80s, ciprofloxacin was introduced as firstline therapy for Salmonella enterica serotype Typhi and Paratyphi A [1].

Subsequently, nalidixic acid resistant $S$. Typhi (NARST) with decreased susceptibility to ciprofloxacin (0.125-1 $\mu \mathrm{g} /$ L), causing therapeutic failure, emerged worldwide and has become endemic in the Indian subcontinent [2]. Molecularly, this was attributed to a single mutation in a quinolone resistance-determining region (QRDR) of gyrA. Resistant isolates harbor two or more mutations in $g y r A$ or $g y r B$ or topoisomerase ( $\operatorname{parC}$ and parE). Other mechanisms, such as multi-antibiotic resistance associated efflux pumps (MAR locus), bacterial permeability, qnr plasmid and up/down regulation of operon genes, have been demonstrated recently [3-5]. There have been isolated reports of ciprofloxacin resistance in $S$. Typhi, from India [6-8] and elsewhere [9]. Nonetheless, high-level fluoroquinolone resistance in non-enteric fever salmonellae is frequent, with MICs ranging from 16-64 $\mu \mathrm{g} / \mathrm{mL}$ [10-12]. Molecular analysis studies of fluoroquinolone resistance or decreased susceptibility in clinical isolates of $S$. Typhi are relatively scarce from India $[6,13]$. We examined the incidence of NARST, decreased susceptibility to ciprofloxacin and made molecular analyses of these strains.

Received on 21 February 2007; revised 26 July 2007.

Address for correspondence: Dr. Deepthi Nair. D-2/2201, Vasant Kunj. New Delhi-110070-India. E-mail: deepthinair67@yahoo.co.in.

The Brazilian Journal of Infectious Diseases 2007;11(4):423-425. (C) 2007 by The Brazilian Journal of Infectious Diseases and Contexto Publishing. All rights reserved.

\section{Materials and Methods}

The study was conducted in a 1,700-bed referral hospital in New Delhi over a period of sixteen months (January 2001 - May 2003). One-hundred-seventy-eight isolates of $S$. Typhi from suspected enteric fever patients were identified by biochemical reactions and serotyping with specific antisera (Central Research Institute, Kasauli, India). The antimicrobial screening of the isolates was done by the disk diffusion method of Kirby Bauer on Mueller Hinton agar using, ampicillin $(10 \mu \mathrm{g})$, chloramphenicol $(30 \mu \mathrm{g})$, trimethoprim/sulfamethoxazole (1.25/ $23.75 \mu \mathrm{g})$, nalidixic acid $(30 \mu \mathrm{g})$, ciprofloxacin $(5 \mu \mathrm{g})$, ceftriaxone $(30 \mu \mathrm{g})$, cefixime $(5 \mu \mathrm{g})$ and cefepime $(30 \mu \mathrm{g})$. The MIC for ciprofloxacin was determined with the agar dilution method. Interpretive criteria for sensitive, intermediate, and resistant strains was $\leq 1 \mu \mathrm{g} / \mathrm{mL},=2 \mu \mathrm{g} / \mathrm{mL}, \geq 4 \mu \mathrm{g} / \mathrm{mL}$, respectively, in accordance with CLSI guidelines [14]. Decreased susceptibility to ciprofloxacin was defined as strains having MIC $\geq 0.125 \mu \mathrm{g} /$ $\mathrm{mL}$ but $\leq 1 \mu \mathrm{g} / \mathrm{mL}$. The control strain was E. coli ATCC 25922 . Antimicrobial disks and antibiotics used in the study were purchased from Hi Media laboratories, India.

Polymerase chain reaction (PCR) amplification and direct DNA sequencing of QRDR regions ( gyrA, gyrB, parC, parE genes) were performed as described by Giraud et al. [15], with an ABI prism dye terminator (Perkin-Elmer, Applied Biosystems, Foster city, California, USA) on an ABI 3730 automated sequencer.

The known-sequence genes were used for designing primers. Oligonucleotide primers used for PCR assay were:

gyrA (F): 5'CCAGATGT(A/C/T)CG(A/C/T)GATGG-3'(F)

gyrA (R): 5'ACGAAATCAAC(G/C)GT(C/T)TCTTTTTC-3' gyrB5 (F): 5'AAGCGCGATGGCAAAGAAG-3' gyrB6 (R): 5'AACGGTCTGCTCATCAGAAAGG-3' $\operatorname{parC3}(\mathrm{F}): 5$ ' CGATTTTCCGGTCTTCTTCCAG3' parC10 (R): 5' GCAATGCACGAATAAACAACGG 3' parE3 (F): 5' CCTGATCTGGCTACTGCAACAG 3' parE8 (R): 5'ATGCGCAAGTGTCGCCATCAG3'. 
The amplified PCR products of eight strains of $S$. Typhi that showed decreased susceptibility/resistance to ciprofloxacin were sequenced; four isolates of NASST were also sequenced. Nucleotide and deduced amino acids were analyzed, using Sequence Navigator Software, followed by blast at the National Center for Biotechnology Information website (http://www.ncbi.nlm.nih.gov/blast).

The qnr plasmid was detected [4] using primers 5' GGG TAT GGA TAT TAT TGA TAA 3' and 5' CTAATC CGG CAG CAC TAT ATA 3 '.

\section{Results}

The disk diffusion method revealed the following resistance pattern: ampicillin 57 (32\%), chloramphenicol 73 (41.4\%), trimethoprim/ sulfamethoxazole $57(32.1 \%)$, nalidixic acid $91(51 \%)$, ciprofloxacin $1(0.6 \%)$, ceftriaxone $1(0.6 \%)$, cefixime $0(0 \%)$, and cefepime $0(0 \%)$. Multidrug resistance (ACCo) was seen in $32 \%$ of the isolates.

Table1. Agar dilution MIC of $S$. Typhi to ciprofloxacin

\begin{tabular}{cc}
\hline MIC range $(\boldsymbol{\mu g} / \mathbf{m L})$ & Ciprofloxacin $^{*}$ \\
\hline$<0.0313$ & 9 \\
0.063 & 78 \\
0.125 & 75 \\
0.250 & 10 \\
0.5 & 3 \\
1 & 2 \\
2 & 0 \\
4 & 1 \\
8 & 0 \\
16 & 0 \\
Total & 178 \\
\hline
\end{tabular}

"Interpretive criteria (CLSI, 2005) for $S$. Typhi for sensitive, intermediate resistant strains, respectively for: ciprofloxacin: $\leq 1 \mu \mathrm{g} / \mathrm{mL},=2 \mu \mathrm{g} / \mathrm{mL}, \geq 4 \mu \mathrm{g} / \mathrm{mL}$.
Agar dilution MIC testing of $S$. Typhi against ciprofloxacin is shown in Table 1. The MIC 90 for ciprofloxacin was $0.125 \mu \mathrm{g}$ $/ \mathrm{mL}$. A single strain was resistant to ciprofloxacin $(4 \mu \mathrm{g} / \mathrm{mL})$. Nalidixic-acid resistant $S$. Typhi (NARST) was observed in $51 \%$ of the isolates, among which $98.9 \%$ had decreased susceptibility (MIC $\geq 0.125-1 \mu \mathrm{g} / \mathrm{mL}$ ) to ciprofloxacin. Seven, randomly selected isolates of NARST and the only ciprofloxacin resistant isolate of $S$. Typhi were molecularly analyzed. In the ciprofloxacin resistant strain, double mutations were found in the gyrA gene (76 Asp $\rightarrow$ Asn, 44 Leu $\rightarrow$ Ileu). Out of 7 NARST, a single mutation was found in five strains (one isolate with $76 \mathrm{Asp} \rightarrow \mathrm{Asn}$; two each with mutations at $87 \mathrm{Asp} \rightarrow$ Asn and $72 \mathrm{Phe} \rightarrow$ Tyr) and no mutations were found in two isolates of NARST. The MICs of these isolates and their molecular analyses are depicted in Table 2. Nalidixic-acid-susceptible $S$. Typhi (NASST) had MICs ranging from $<0.0313-0.063 \mu \mathrm{g} / \mathrm{mL}$, and the $g y r A$ mutation was not observed (Table 1).

\section{Discussion}

Multi-drug resistance (ACCO) was observed in 32\% of the strains. Currently, the incidence of MDRST varies from $25 \%-55 \%$ in India [16]. Some studies have reported higher rates $(65 \%)$ from abroad [17]. Since 2000, a re-emergence of sensitivity to the classical first-line agents has been observed, due to their restricted use in the "ciprofloxacin era" of the 1990s. There has been a concomitant decrease in susceptibility to ciprofloxacin and nalidixic acid in this region $[13,18,19]$.

The incidence of NARST was 51\%. Other researchers from India have reported incidences varying from $47 \%$ to $100 \%$ $[13,18,19]$. However, in developed countries, NARST incidence has been reported to be much lower $(0 \%-17 \%)[17,20]$. In our study, a single strain $(0.6 \%)$ of $S$. Typhi was found resistant to ciprofloxacin at $4 \mu \mathrm{g} / \mathrm{mL}$. This strain was isolated from a patient

Table 2. Mutations in DNA gyrase, topoisomerase $I V$ and the $q n r$ plasmid in $S$. Typhi isolates associated with decreased susceptibility or resistance to ciprofloxacin ${ }^{\mathrm{a}}$

\begin{tabular}{|c|c|c|c|c|c|c|c|}
\hline SNO & $\begin{array}{l}\mathbf{N A}^{\mathbf{b}} \\
\mathbf{M I C}\end{array}$ & $\begin{array}{l}\mathbf{C P}^{\mathbf{c}} \\
\text { MIC }\end{array}$ & gyrA & $\operatorname{gyr} B$ & parC & parE & $q n r$ \\
\hline 1 & $\geq 256$ (NARST) & 0.125 & $87 \mathrm{Asp} \rightarrow$ Asn & $\mathrm{NP}^{\mathrm{d}}$ & NP & NP & NP \\
\hline 2 & $\geq 256$ (NARST) & 0.5 & $87 \mathrm{Asp} \rightarrow \mathrm{Asn}$ & $\mathrm{NP}$ & $\mathrm{NP}$ & $\mathrm{NP}$ & $\mathrm{NP}$ \\
\hline 3 & $\geq 256$ (NARST) & 0.5 & $72 \mathrm{Phe} \rightarrow \mathrm{Tyr}$ & $\mathrm{NP}$ & $\mathrm{NP}$ & $\mathrm{NP}$ & NP \\
\hline 4 & $\geq 256$ (NARST) & 0.25 & $72 \mathrm{Phe} \rightarrow \mathrm{Tyr}$ & $\mathrm{NP}$ & $\mathrm{NP}$ & $\mathrm{NP}$ & NP \\
\hline 5 & $\geq 256$ (NARST) & 0.25 & $76 \mathrm{Asp} \rightarrow$ Asn & $\mathrm{NP}$ & $\mathrm{NP}$ & $\mathrm{NP}$ & $\mathrm{NP}$ \\
\hline 6 & $\geq 256$ (NARST) & 0.25 & $\mathrm{NP}$ & $\mathrm{NP}$ & $\mathrm{NP}$ & NP & $\mathrm{NP}$ \\
\hline 7 & $\geq 256$ (NARST) & 0.5 & $\mathrm{NP}$ & $\mathrm{NP}$ & $\mathrm{NP}$ & $\mathrm{NP}$ & $\mathrm{NP}$ \\
\hline 9 & 8 (NASST) & 0.063 & NP & $\mathrm{NP}$ & NP & $\mathrm{NP}$ & NP \\
\hline 10 & 8 (NASST) & 0.063 & $\mathrm{NP}$ & NP & NP & NP & $\mathrm{NP}$ \\
\hline 11 & 8 (NASST) & 0.063 & $\mathrm{NP}$ & $\mathrm{NP}$ & $\mathrm{NP}$ & $\mathrm{NP}$ & $\mathrm{NP}$ \\
\hline 12 & 8 (NASST) & 0.063 & $\mathrm{NP}$ & $\mathrm{NP}$ & $\mathrm{NP}$ & $\mathrm{NP}$ & $\mathrm{NP}$ \\
\hline
\end{tabular}

a $g y r B, \operatorname{par} C$, parE mutations and $q n r$ plasmid were not present. ${ }^{b}$ Nalidixic acid; NARST: nalidixic acid resistant $S$. Typhi; NASST: nalidixic acid sensitive $S$. Typhi; ${ }^{\mathrm{c}}$ Ciprofloxacin; ${ }^{\mathrm{d}} \mathrm{NP}$ : not present. 
in 2003; this patient had been prescribed broad-spectrum antimicrobials, including fluoroquinolones. A report from the National Salmonella Phage Typing Center in India showed similar findings, with $0.56 \%$ of $S$. Typhi being resistant and $39.96 \%$ with an intermediate MIC to ciprofloxacin [21]. Most of the NARST (98.9\%) had decreased susceptibility to ciprofloxacin (MIC $\geq 0.125$ $\mu \mathrm{g} / \mathrm{mL})$. Several workers have corroborated this finding abroad [3] and in India [19]. The use of CLSI breakpoints of resistance to ciprofloxacin in $S$. Typhi at $\geq 4 \mu \mathrm{g} / \mathrm{mL}$ has been suggested to obscure the true occurrence of resistance. There have been recommendations that the MIC cut-off should be reduced to $\geq 0.125 \mu \mathrm{g} / \mathrm{mL}$ for redefining resistance [3]. Recent literature demonstrated isolated reports of ciprofloxacin resistance in $S$. Typhi, from India and elsewhere [7-9]. Selective pressures exerted by over prescription of drugs, easy availability, use of spurious antimicrobials, overuse in veterinary medicine, etc., may make such isolates more common in the future.

We identified a novel replacement in the gyrA gene at 76 $\mathrm{Asp} \rightarrow$ Asn and $44 \mathrm{Leu} \rightarrow$ Ileu, which conferred a resistant MIC level of $4 \mu \mathrm{g} / \mathrm{mL}$. These types of gyrA mutations have not been observed previously in $S$. Typhi, S. Paratyphi A, other salmonellae or $E$. coli. [3,4,12,15,20,22,23]. Due to the paucity of sequencing data of isolates of $S$. Typhi clinically resistant to ciprofloxacin, such substitutions could not be compared; however, they may appear in future. Single $87 \mathrm{Asp} \rightarrow$ Asn substitution in $g y r A$ of two NARST strains is a common association reported with NARST $[3,12,20]$. Nonetheless, the single mutations seen in a NARST isolate at $76 \mathrm{Asp} \rightarrow$ Asn were hitherto unknown [3,12,13,20]. However, there is a single report of $72 \mathrm{Phe} \rightarrow$ Tyr substitution in $S$. Seftefberg, in combination with $83 \mathrm{Ser} \rightarrow$ Phe [10].

As mutations were not found in two NARST strains, other possibilities, such as other mechanisms, including efflux pumps, plasmids, etc, involved in quinolone resistance can not be ruled out in our study.

In India, which has a large reservoir of NARST strains that are converting to quinolone resistance, treatment failure with quinolones is now the norm. The first-line antimicrobials need to be revisited. The third and fourth generation cephalosporins are treatment alternatives, although resistance [24] is gradually surfacing to these drugs. A larger study with multiple isolates showing resistance to ciprofloxacin conferred by multiple mutations, and their subsequent epidemiological typing, is required to confirm clonal vis-à-vis de-novo mutation. However, detection of isolates with decreased susceptibilities towards fluoroquinolones is crucial, as these are capable of becoming highly resistant in the near future. The finding of gyrA mutations is a serious concern and beckons continuous monitoring of fluoroquinolone resistance in $S$. Typhi for determining effective treatment policies.

\section{References}

1. Threlfall E.J., Ward L.R., Skinner J.A., et al. Ciprofloxacinresistant Salmonella typhi and treatment failure. Lancet 1999;353:1590-1.

2. Threlfall E.J., Ward L.R. Decreased susceptibility to ciprofloxacin in Salmonella enterica serovar Typhi, United Kingdom. Emerg Infect Dis 2001;7:1-6.
3. Crump J.A., Barrett T.J., Nelson J.J., Angulo F.J. Re-evaluating fluoroquinolone breakpoints for Salmonella enterica serotype Typhi and for Non-Typhi Salmonellae. Clin Infect Dis 2003; $37: 75-81$

4. Nair S., Unnikrishnan M., Turner K., et al. Molecular analysis of fluoroquinolone-resistant Salmonella Paratyphi A isolate, India. Emerg Infect Dis 2006;12:489-1.

5. Hirose K., Hashimoto A., Tamura K., et al. DNA sequence analysis of DNA gyrase and DNA topoisomerase in the quinolone resistance determining regions of Salmonella enterica serovar Typhi and serovar Paratyphi A. Antimicrob Agents Chemother 2002; 46 :3249-52

6. Renuka K., Sood S., Das B.K., Kapil A. High-level ciprofloxacin resistance in Salmonella enterica serovar Typhi in India. J Med Microbiol 2005;54:999-1000.

7. Mohanty S., Renuka K., Sood S., et al. Antibiogram pattern and seasonality of Salmonella serotypes in a North Indian tertiary care hospital. Epidemiol Infect 2006;14:1-6.

8. Joshi S., Amarnath S.K. Fluoroquinolone resistance in Salmonella typhi and S. paratyphi A in Bangalore, India. Trans R Soc Trop Med Hyg 2007;101:308-10.

9. Cooke F.J., Wain J., Threlfall E.J. Fluoquinolone resistance in Salmonella enterica serovar Typhi. B Med J 2006;33:353-4.

10. Eaves D.J., Randall L., Gray D.T., et al. Prevalence of mutations within the quinolone resistance determining region of gyrA, $\operatorname{gyr} B, \operatorname{parC}$, and $\operatorname{parE}$ and association with antibiotic resistance in quinolone-resistance Salmonella enterica. Antimicrob Agents Chemother 2004; $48: 4012-5$.

11. Baucheron S., Chaslus-Dancla E., Cloeckaert A., et al. High level resistance to fluoroquinolones linked to mutations in gyr A, par $\mathrm{C}$ and par E in Salmonella enterica serovar Schwarzengrund isolated from humans in Taiwan. Antimicrob Agents Chemother 2005; 49 : $862-3$

12. Ling J.M., Chan E.W., Lam A., et al. Mutations in topoisomerase genes of fluoroquinolone resistant Salmonella in Hong Kong. Antimicrob Agents Chemother 2003; 47:3567-73.

13. Renuka K., Kapil A., Kabra S.K., et al. Reduced susceptibility to ciprofloxacin and gyrA gene mutation in North Indian strains of Salmonella enterica serotype Typhi and serotype Paratyphi A. Microb Drug Resist 2004;10:146-53.

14. Clinical and Laboratory Standards Institute. Performance Standards for Antimicrobial Susceptibility testings. Fifteenth Informational Supplement. CLSI document M100-S15. Clinical and Laboratory Standards Institute, 2005, Wayne, PA.

15. Giraud E., Brisabois A., Martel J.L., Chaslus-Dancula E. Comparative study of animal isolates and experimental in vitro- and in vivoselected mutants of Salmonella spp. suggest a counterselection of highly fluoroquinolone-resistant strains in the field. Antimicrob Agents Chemother 1999;43:2131-7.

16. Gautam V., Gupta N.K., Chaudhary U., Arora D.R. Sensitivity pattern of Salmonella serotypes in Northern India. Braz J Infect Dis $2002 ; 6: 1-9$.

17. Kariuki S., Gilks C., Revathi G., Hart A.C. Genotypic analysis of multidrug- resistant Salmonella enterica serovar Typhi, Kenya. Emerg Infect Dis 2000;6:649-51.

18. Mandal S., Mandal M.D., Pal N.K. Reduced minimum inhibitory concentrations of chloramphenicol for Salmonella enterica serovar Typhi. Ind J Med Sci 2004:58:16-23.

19. Kadhiravaran T., Wig N., Kapil A., et al. Clinical outcomes in typhoid fever: adverse impact of infection with nalidixic acidresistant Salmonella typhi. BMC Infect Dis 2005;5:2334-7.

20. Hirose K., Tamura K., Sagara H. Watanabe H. Antibiotic susceptibilities of Salmonella enterica serovar Typhi and S. enterica serovar Paratyphi A isolated from patients in Japan. Antimicrob. Agents Chemother 2001;45:956-8.

21. Mehta G., Randhawa V.S., Mohapatra N.P. Intermediate susceptibility to ciprofloxacin in Salmonella typhi strains in India. Eur J Clin Microbiol Infect Dis 2001;20:760-1.

22. Adachi T., Sagara H., Hirose K., Watanabe H. Fluoroquinoloneresistant Salmonella enterica serovar Paratyphi A. Emerg Infect Dis 2005; $11: 172-4$.

23. Friedman S.M., Lu T., Drlica K. Mutation in the DNA gyrase A gene of Escherichia coli that expands the quinolone resistancedetermining region. Antimicrob Agents Chemother 2001; 45:2378-80

24. Marano N., Stamey K., Barrett T.J., et al. Emerging quinolone and extended spectrum cephalosporin resistant Salmonella in the United States. American Society for Microbiology, $99^{\text {th }}$ General Meeting. Chicago, IL, May 1999. 